\title{
PRÁTICAS EDUCATIVAS E DIREITOS HUMANOS: DA LEGALIDADE DO PROGRAMA EDUCACIONAL DE RESISTÊNCIA ÀS DROGAS E À VIOLÊNCIA- PROERD
}

\section{ARTIGO ORIGINAL}

CIPRIANI, Taciane Andreghetto ${ }^{1}$

CIPRIANI, Taciane Andreghetto. Práticas Educativas e Direitos Humanos: Da Legalidade do Programa Educacional de Resistência às Drogas e à ViolênciaPROERD. Revista Científica Multidisciplinar Núcleo do Conhecimento. Ano 05, Ed. 05, Vol. 10, pp. 141-154. Maio de 2020. ISSN: 2448-0959, Link de acesso: https://www.nucleodoconhecimento.com.br/lei/resistencia-as-drogas

\section{RESUMO}

O presente trabalho de pesquisa tem por objetivo sopesar o papel do Programa Educacional de Resistência às Drogas e à Violência - PROERD, e suas questões legais, que se baseiam na ação de política preventiva e conscientização junto às escolas nas series fundamentais iniciais, bem como esclarecer o funcionamento do referido programa. Destarte, os objetivos traçados com o referido estudo é afirmar a eficácia do mesmo enquanto programa educativo de prevenção. O estudo fora realizado por meio de pesquisa qualitativa através de pesquisa bibliográfica em fontes impressas e on-line. Constatou-se, como esperado, que o programa de cunho preventivo de resistência às drogas e à violência, é uma ação política eficiente quanto à segurança social, amparado pela legislação vigente. Diante do viés positivo, uma proposta de melhoria do trabalho já realizado seria a expansão do programa,

\footnotetext{
${ }^{1}$ Mestranda em Desenvolvimento Regional pela Universidade Tecnológica Federal do Paraná- UTFPR (2019/2021); pós-graduada em Processo Civil pelo Centro Universitário Internacional- UNINTER (2016), Pós- Graduada em Gestão Pública com ênfase em Direitos Humanos (2019). Possui graduação em Direito pelo Centro Sulamericano de Ensino Superior - CESUL (2014).
} 
cumprindo todos os currículos disponíveis, quais sejam: PROERD kids; PROERD 5o ano; PROERD $7^{\circ}$ ano e PROERD Pais.

Palavras-chaves: PROERD, drogas, educação.

\section{INTRODUÇÃO}

Todos os dias, nos deparamos com trágicas notícias, seja pela mídia televisiva, jornais ou redes sociais. A grande maioria diz respeito ao aumento da violência e criminalidade, diretamente relacionado ao consumo de drogas, e quão jovens são os autores de tais atos infracionais (que são as condutas descritas como crime cometidas por criança ou adolescente). Esses jovens sem educação e sem perspectiva, buscam no tráfico a sua sobrevivência.

De fato, não é de hoje que os olhos da sociedade e do Estado estão voltados para esse problema, buscando prevenir a entrada dos jovens e adolescentes no mundo das drogas e do crime, o que se torna um problema social e de saúde pública. Nas conferências internacionais se abordaram a formação para as políticas públicas sobre álcool e outras drogas na perspectiva dos direitos humano (DALLA VECCHIA, 2017).

Nesta seara os Direitos Humanos são direitos inerentes a todos os seres humanos, independente de raça, sexo, ou qualquer oura condição, (NAÇÕES UNIDAS DO BRASIL, 2018).

Como explanado, os direitos humanos atingem uma gama muito ampla de direitos, e tendo como premissa a defesa da educação como direito humano em benefício dos cidadãos e do próprio desenvolvimento do país, o Estado possui a responsabilidade de assegurar o cumprimento destes direitos em todas as esferas sociais, utilizandose de políticas públicas.

Dentro desta perspectiva de direitos humanos e educação, destaca-se o PROERD Programa Educacional de Resistência às Drogas e à Violência, que se baseia em ações educativas preventivas, aplicado dentro das escolas para alunos do ensino 
fundamental, trabalhando de forma preventiva ao uso de drogas e consequentemente a violência.

Cabendo discutir sua eficácia e legalidade, objetivou-se discorrer sobre as praticas educativas e esclarecer como o programa surgiu e como ele é realizado e seu alcance legal.

Através da aplicação da legislação vigente no país no que diz respeito à aplicação dos Direitos Humanos na educação para construção de uma sociedade mais justa, para isso, o referido trabalho se deu por meio de pesquisa bibliográfica vasta, e, experiência profissional da pesquisadora, que atuou como Educadora Social do Proerd.

O trabalho de pesquisa desenvolvido buscou obter informações fidedignas sobre o viés pedagógico e legal do programa social PROERD, desenvolvido nas escolas da rede pública e privada do Paraná, assinala elementos importantes para uma análise da importância do programa e de sua legalidade jurídica.

Destarte, a problemática levantada incita uma ação fulgente, tornando-se necessário utilizar-se de uma metodologia que satisfaça aos objetivos propostos. Fora realizada uma vasta pesquisa bibliográfica que auxiliou teoricamente o presente artigo, que se realiza a partir do registro disponível, decorrente de pesquisas anteriores, em documentos impressos, como livros, artigo, teses e outros (SEVERINO, 2007).

A metodologia aplicada no desenvolvimento do presente estudo foi o método dedutivo, caracterizando-se por pesquisa bibliográfica de abordagem qualitativa e explicativa, através de bibliografias e artigos científicos, são varias metodologias de pesquisa que podem adotar uma abordagem qualitativa, faz referencia mais a seus fundamentos epistemológicos do que propriamente a especificidades metodológicas (SEVERINO, 2007).

\section{PRÁtICAS EDUCATIVAS E AS CONTRIBUIÇÕES DO PROERD}

As mudanças sociais em que se vive e as complexidades apresentadas diariamente na escola e na sala de aula, não comportam mais a relação restrita professor e o 
aluno, por isso, há uma necessidade de expandir os atores do cenário educacional inserindo outros membros da sociedade para que haja uma interação com os alunos, contribuindo para o aprendizado e crescimento do aluno como cidadão. Nesse cenário surge o programa PROERD.

Segundo Melo (2011, p.8)

Educação é muito mais que aprendizado de conhecimentos, e o processo de aprendizado na escola também leva em conta outras questões, como a vida familiar, a situação econômica e, no caso que nos afeta mais diretamente neste livro, a participação da comunidade na escola.

Somos socialmente construídos e da mesma forma que somos construídos, construímos a sociedade. Modelando-se juntos, por meio das relações sociais que estabelecemos com os outros, iguais a nós, e com a natureza (MICHALISZYN, 2012).

Desta forma, quanto mais relações interpessoais e interculturais houver no ambiente escolar, mais fragmentos consolidarão a formação do aluno e do indivíduo social.

De acordo com Perovano (2006), o educador deve trabalhar de forma a prevenir e intervir em situações de risco social, de forma a criar mudanças e exercer intencionalmente influências positivas nos indivíduos, sendo que a educação social atua simultaneamente com outros trabalhadores sociais de modo interdisciplinar na proteção e ascensão sociais.

A educação para a cidadania requer que questões sociais sejam apresentadas para os alunos, pois a escola não muda a sociedade, mas pode constituir-se como espaço de transformação (BRASIL, 1997).

Destarte, o tema drogas é apresentado, transversalmente, por um Policial Militar, inserido no ambiente escolar por sua complexidade, desafia as instituições e requer uma abertura da escola para saber perceber as expressões vitais próprias da existência de todo ser humano (RATEKE, 2006). 
O trabalho com questões sociais exige preparo dos educadores para lidar com questões inesperadas, as quais devem responder com clareza e pontualidade (PARÂMETROS CURRÍCULARES NACIONAIS, 2001, p. 55).

$\mathrm{Na}$ educação fundamental, muitos professores não se sentem preparados para desenvolver temas sociais mais comuns com seus alunos, como meio ambiente, sexualidade, prevenção ao uso/abuso de drogas, cultura de paz, e tantos outros recorrentes, que se constituem fundamentais para a construção do senso de cidadania para a criança e o adolescente. (PEROVANO, 2006, p. 22).

O PROERD, realizado com séries escolares específicas, possui o objetivo de intervir junto aos demais setores sociais, através de ações que os alunos aprendam ou modifiquem devido ao programa.

Em seu procedimento metodológico, o programa prevê a participação da família em algumas atividades a serem desenvolvidas, fazendo com que familiares participem na educação e no desenvolvimento dos alunos, para que estes compartilhem o aprendizado das aulas sobre as drogas e a violência. Atingindo assim, indiretamente, um maior número de pessoas. Nesta perspectiva, a educação formal é um espaço, mas não o único, para o trabalho de prevenção as drogas, devendo ser agregada a esforços de diferentes áreas do conhecimento e setores da organização social (PEROVANO, 2006).

Torna-se assim um dever de toda a comunidade, colaborar para a proteção das crianças e adolescentes no perímetro escolar e arredores, assim como toda a sociedade se torna colaboradora na prevenção as drogas e a violência, não deixando que indivíduos mal intencionados se aproximem da escola, podendo colaborar através de denúncias. 


\section{CONHECENDO O PROGRAMA EDUCACIONAL DE RESISTÊNCIA ÀS DROGAS E À VIOLÊNCIA (PROERD)}

O PROERD é um programa fomentado pelo Ministério da Justiça, em torno de um eixo estratégico comum, o que é a prevenção primária ao uso de psicotrópicos principalmente por crianças em idade escolar.

O Programa PROERD se autorreferência como uma proposta de “inovação" pedagógica no campo da prevenção. Em meio ao contexto educacional recente e em crise, inovar é uma necessidade existencial, elogiada e solicitada pelas escolas e pela comunidade. Periodicamente, assiste-se ao surgimento aguardado de algum salva-vidas, com novidades e soluções sempre mágicas e pretensamente transformadoras do degenerado presente. (RATEKE, 2006, p.72).

De cunho preventivo, usando a técnica de polícia comunitária, busca aproximar a comunidade da Polícia Militar do Paraná para que seja estabelecida uma sensação de segurança e confiança, unindo esforços de três eixos basilares a Escola a Família e a Polícia Militar (CURSO NACIONAL DE INSTRUTORES PROERD, 2015).

De acordo com o Curso Nacional de Promotor de Polícia Comunitária (2009), a ideia central da Polícia Comunitária esta na possibilidade de proporcionar uma aproximação dos profissionais de segurança junto à comunidade onde atua.

O policiamento comunitário foi adotado como forma de melhorar o relacionamento entre polícia e comunidade, reconstruindo a confiança da população naquela instituição, melhorando a segurança pública. (MANUAL DE POLICIAMENTO COMUNITÁRIO, 2009).

Desta forma o Proerd é o maior programa de policia comunitária existente atualmente com resultados positivos no Brasil e muitos outros países, criado por um a equipe multidisciplinar, formada por psicólogos, educadores e policiais, além de falar para crianças e adolescentes sobre os malefícios do uso indevido das drogas e suas 
consequência, criar uma relação de confiança entre a Polícia Militar e a comunidade (SOARES, 2016).

Baseado no programa americano D.A.R.E - Drug Abuse Resistance Education, desenvolvido inicialmente em 1983, em Los Angeles, a Polícia Militar do Estado de Rio de Janeiro, em 1992, implantou o PROERD nas escolas daquele Estado, e a partir de 2002, o programa se expandiu para os demais Estados brasileiros (PMPR, 2018).

[...] ficou acordado, com a Embaixada Americana, o comparecimento de uma equipe de profissionais do Departamento de Los Angeles para treinar policiais militares do Rio de Janeiro. A vinda dessa equipe, em agosto de 1992, oficializou a chegada do Programa no país. Em 1993, ocorreu a vinda de uma nova equipe, fazendo com que a Polícia Militar do Estado do Rio de Janeiro constituísse o primeiro Centro de Treinamento do Brasil. No país, a adaptação do DARE a nossa realidade se ateve a transformações da sigla e à aplicação do Programa para crianças da quarta série[2] do ensino fundamental. Já os aspetos pedagógicos não sofreram mudanças. Com isso surgiu aqui o Programa Educacional de Resistência às Drogas e à Violência. ( RATEKE, 2006, p.42). (grifou-se).

O Programa se baseia em aulas ministradas por um instrutor Policial, que através de uma metodologia específica, focando em atividades de resistência e prevenção às drogas e à violência, desenvolve nos alunos a percepção de tomarem decisões seguras e responsáveis. De acordo com Perovano (2006), com a premissa de que o PROERD, antecipa-se à oferta de drogas se busca desenvolver um trabalho não repressivo, pois essa forma apresenta resultados históricos negativos.

Assim utilizando-se da pedagogia social, com olhar crítico e esperançoso de mudanças na vida dos jovens e adolescentes alcançados pelo programa. Se almejam outros objetivos, conforme Soares (2016) o PROERD busca uma construção de confiança entre a polícia e a comunidade, se tornando uma parceria confiável e amiga , também pode ser trabalhada de modo que o Policial Militar em contato com a reali- 
dade dos jovens conviveria com as limitações que os mesmos enfrentam na sua formação de personalidade (SOARES, 2016).

Sem perceber-se se encontra-se em guerra constante contra as drogas e consequentemente a violência, sendo que a prevenção em longo prazo pode ser mais eficiente, evitando que aqueles que nunca tiveram contato, ou, pela tenra idade não deveriam ainda ter tido contato com substâncias psicotrópicas, o façam; o PROERD, apesar de realizado com algumas séries escolares, através das atitudes que os alunos aprendem ou modificam devido à participação no programa, atingem toda uma comunidade (DEMETRIO, 2013).

No Paraná, o foco do programa são os alunos do $5^{\circ}$ ano do ensino fundamental de escolas públicas e privadas. De acordo com o currículo do Programa, as aulas permitem que o aluno compreenda os efeitos das drogas no organismo, e as consequências de seu uso. As aulas são ministradas por policiais militares que se tornam educadores sociais. Estes profissionais são previamente capacitados para o programa e em condições de atender aos alunos desta faixa etária. (SESP, 2018).

Além dos alunos em sala de aula terem a oportunidade de se aproximar dos policiais, e tirarem dúvidas sobre diversos assuntos, desmistifica-se conceitos apresentados de forma errada pela sociedade, criando assim um vínculo de confiança e respeito.

E é em sala de aula com a aproximação e confiança do Policial Militar, que muitos outros problemas acabam por ser revelados, exemplo disso são os relatos de violência e abuso sexual, que alunos e alunas acabam por relatar por ver naquele policial uma pessoa de confiança que poderá lhe ajudar a acabar com tanto sofrimento.

\section{DO ASPECTO LEGAL DO PROERD (PROGRAMA EDUCACIONAL DE RESISTÊNCIA ÀS DROGAS E À VIOLÊNCIA}

Atualmente, existem três acordos internacionais que regulam o tema Drogas; quais sejam: A Convenção Única da ONU sobre Entorpecentes, de 1961; A Convenção da ONU sobre Substâncias Psicotrópicas, de 1971; A Convenção da ONU contra o 
Tráfico llícito de Entorpecentes e Substâncias Psicotrópicas, de 1988. No Brasil a legislação mais recente é a lei no 11.343/06, que institui o Sistema Nacional de Políticas Públicas sobre Drogas - Sisnad; e prevê atividades de prevenção ao uso indevido de drogas, principalmente no tocante as crianças e adolescentes; vejamos:

Art. 19. As atividades de prevenção do uso indevido de drogas devem observar os seguintes princípios e diretrizes:

[...] XI - a implantação de projetos pedagógicos de prevenção do uso indevido de drogas, nas instituições de ensino público e privado, alinhados às Diretrizes Curriculares Nacionais e aos conhecimentos relacionados a drogas;

[...] Parágrafo único. As atividades de prevenção do uso indevido de drogas dirigidas à criança e ao adolescente deverão estar em consonância com as diretrizes emanadas pelo Conselho Nacional dos Direitos da Criança e do Adolescente - Conanda. (BRASIL, 2006).

Também, existe a Política Nacional Sobre Drogas, política esta, que se orienta pelo principio da responsabilidade mutua, através de articulações entre governo, sociedade e iniciativa privada para o combate as drogas. (BRASIL; POLÍTICAS SOBRE DROGAS, 2011).

Essa forma de regramento busca construir uma sociedade protegida do uso de drogas ilícitas, e do uso indevido de drogas lícitas, bem como garantir a implantação e efetivação de melhorias dos programas de prevenção e tratamento ao uso de drogas.

Além disso, as ações preventivas devem ser planejadas e direcionadas ao desenvolvimento humano e incentivo a educação e a vida saudável, assim como, propor a inclusão na educação básica e superior de conteúdos relativos à prevenção do uso indevido de drogas (POLÍTICAS SOBRE DROGAS, 2011). Direitos Humanos devem ser trabalhados na escola na forma de conteúdos relativos aos direitos humanos e à prevenção de todas as formas de violência contra a criança e o adolescente , como temas transversais (BRASIL, 1996). 
Portanto, as ações preventivas devem ser pautadas em princípios éticos e na pluralidade cultural, orientadas para a promoção de valores voltados à saúde física e mental, individual e coletiva, ao bem-estar, à integração socioeconômica e a valorização das relações familiares, considerando seus diferentes modelos. Além disso, devem ser planejadas e direcionadas ao desenvolvimento humano, com incentivo à educação para a vida saudável, acesso aos bens culturais, incluindo a prática de esportes, cultura, lazer, a socialização do conhecimento sobre drogas com embasamento científico, o fomento ao protagonismo juvenil, à participação da família, da escola e da sociedade na multiplicação dessas ações (MINISTÉRIO DA JUSTIÇA E SEGURANÇA PÚBLICA).

De acordo com a Carta Magna de 1988, compete aos Estados, juntamente com a família e sociedade, assegurar as crianças e adolescentes os direitos e garantias fundamentais do ser humano (BRASIL, 1988).

Ainda de acordo com o art. 144 da Constituição Federal:

Art. 144. A segurança pública, dever do Estado, direito e responsabilidade de todos, é exercida para a preservação da ordem pública e da incolumidade das pessoas e do patrimônio, através dos seguintes órgãos:

I - polícia federal; II - polícia rodoviária federal; III - polícia ferroviária federal; IV - polícias civis V - polícias militares e corpos de bombeiros militares.

§ 1o A polícia federal, instituída por lei como órgão permanente, estruturado em carreira, destina-se a:

\section{$[\ldots]$}


II - prevenir e reprimir o tráfico ilícito de entorpecentes e drogas afins, o contrabando e o descaminho, sem prejuízo da ação fazendária e de outros órgãos públicos nas respectivas áreas de competência;

\section{[...], (grifado).}

Ainda na mesma perspectiva, a Constituição Estadual do Paraná de 1989, em seu Art. 220, incisos III e IV, determina como encargo do Estado, a participação dos Municípios e da Sociedade, na promoção de programas de assistência integral à criança e ao adolescente, dependentes de entorpecentes e drogas afins, realizando cursos, palestras e outras atividades correlatas para a orientação especialmente em campanhas antidrogas (PARANÁ, 1990).

De acordo com Perovano (2006), o Paraná instituiu em 2005, através de Decreto a formação em cidadania plena, para todos os níveis de ensino do Estado com enfoque na prevenção ao uso indevido de drogas lícitas e ilícitas.

$\mathrm{Na}$ seara de legislação federal, o Estatuto da Criança e do Adolescente (ECA), Lei 8.069/90, se compromete, tornado prioridade, a proteção na fase de crescimento e desenvolvimento dos infantes. A criança e o adolescente tem direito a proteção à vida e à saúde, mediante a efetivação de políticas sociais públicas que permitam o nascimento e desenvolvimento sadio e harmonioso, em condições dignas de existência (Art. $7^{\circ}$, lei 8.069/90).

Desta forma todos os programas sociais vêm de encontro com essas premissas, ainda é dever de todos prevenir a ocorrência de ameaça ou de violação dos direitos da criança e do adolescente (Art. 70, lei 8.069/90). Na aplicação das medidas, levar-seão em conta, as necessidades pedagógicas, preferindo-se aquelas que visem o fortalecimento dos vínculos familiares e comunitários. (Art. 100, lei 8.069/90).

No âmbito do Sistema Nacional Antidrogas - SISNAD, a Resolução ํㅡㄴ 24, de 20 de dezembro de 2002, define o PROERD Parceiro Estratégico para as ações de Prevenção Primária. 
No Estado do Paraná, as Secretarias de Estado da Segurança Pública, da Educação e da Justiça e Cidadania, através de seus titulares, assinaram a chamada Resolução Conjunta, que prevê ao Programa o fornecimento de condições de mantê-lo com recursos necessários para a implantação nos municípios e implementações de ações. (PEROVANO, 2006, p. 58).

Percebe-se, que há todo um aparato legal para que o programa PROERD seja mantido e expandido na rede pública, e até mesmo, privada de educação, destacando que para que os municípios recebam o programa estes devem firmar um convênio com o Estado, este disponibiliza através da policia militar os instrutores Proerd e aquele os materiais necessários para a realização do programa.

\section{RESULTADOS E DISCUSSÃO}

O programa social PROERD, inserido nas escolas paranaenses desde meados do ano 2001, vem se expandindo e se aperfeiçoando, atendendo as necessidades apresentadas pela evolução social sem se desvincular do programa original criado nos EUA, ao desenvolver o referido estudo, percebe-se que o programa aborda temas delicados, que muitas vezes, os professores sentem dificuldade de abordar em sala de aula.

Ainda que os instrutores PROERD são denominados Educadores Sociais e não professores, como difundido erroneamente, "o policial-militar, por mais que tenha formação pedagógica, no momento da aplicação das lições do PROERD, cumpre o papel de instrutor, e não de professor" (PEROVANO, 2006, p.21).

Desta forma, a educação vem passando por transformações frequentes precisando se amoldar as novas demandas sociais, respeitando os Direitos Humanos da Criança e Adolescente não podendo se esquivar dos assuntos transversais.

Da visão legal esta amplamente amparado pelas leis nacionais e internacionais. Percebe-se que a questão drogas e violência é uma preocupação a nível mundial, 
onde esforços são unidos na tentativa de combater ou ao menos amenizar o tráfico e uso de entorpecentes e suas consequências. Nesta premissa, prevenir é muito mais eficaz do que reprimir, portanto, os esforços se unem para os programas de prevenção, que a longo prazo mostraram resultados mais satisfatórios e econômicos.

Percebe-se a riqueza da educação social, e se amplia o espaço educacional para além da sala de aula, para além dos professores, promovendo assim interculturalidade, troca de experiências e ganho de confiança, promovendo uma interação mais profunda entre instrutor do Proerd e alunos. Fazendo com que o vinculo de confiança aumente a segurança e auto confiança, para que os alunos já orientados saibam fazer escolhas seguras e digam não há qualquer oferta de drogas sejam elas licitas ou ilícitas.

Somado a isso temos a presença de policiais nas escolas, aumentando a segurança direta, inibindo pessoas mal intencionadas de se aproximarem do perímetro escolar. Afastando desta forma, apenas pela presença de viaturas e policiais as possíveis ofertas de drogas nas redondezas das escolas.

Claro que a oferta pode ocorrer longe das escolas, e é por isso que o programa busca através de resolução de problemas, ensinar as crianças a fazerem escolhas responsáveis em qualquer situação.

\section{CONSIDERAÇÕES FINAIS}

Ao se abordar o tema "Direitos Humanos e Educação", há toda uma gama de ramificações que devem ser consideradas, o que exige dos profissionais envolvidos um amplo conhecimento para satisfazer as necessidades pedagógicas dos educandos.

Entre tantas demandas sociais nos deparamos com a questão da segurança pública, drogas e violência. Assim, são desenvolvidas ações políticas preventivas nas escolas, através de programas como o PROERD, sendo uma ação necessária perante os problemas escolares que, alunos, pais e professores vem enfrentando quanto à 
segurança social dos alunos, as atitudes violentas no âmbito escolar tem se tornado rotineira, ocasionando riscos tanto a alunos quanto aos profissionais da educação que atuam nestas instituições (DEMETRIO, 2013).

Como analisado, o PROERD vem sendo realizado através de atividades educativas preventivas, desenvolvidas nas unidades escolares do Estado do Paraná e outras unidades da federação, buscando intencionalmente levar as crianças e adolescentes a tomarem decisões seguras e responsáveis, quanto ao uso de drogas licitas e elícitas e em relação à violência.

Pode-se observar com a presente pesquisa que o Programa Educacional Proerd, desempenha um papel eficaz em relação aos seus objetivos qual seja a prevenção primaria, cumprindo sua finalidade de política pública quando os alunos levam para dentro de suas casas o aprendizado em sala de aula, contribuindo para a conscientização não só dos alunos que participam do programa educacional, mas de todos os envolvidos.

Do ponto de vista legal, o Programa esta amparado pela Legislação Internacional, Legislação Federal, Constituição Federal de 1988, Lei de Diretrizes e Bases da Educação, Estatuto da Criança e do Adolescente, Constituição estadual e demais acordos e convênios celebrados entre Estados e Municípios, conforme citados na estrutura do texto.

Instiga-se também, uma pesquisa mais profunda, onde oportunamente poderá se levantar uma pesquisa de campo através de entrevistas aos alunos e demais protagonistas do programa, além de levantamento de dados para saber quais municípios são agraciados com o programa, percentual de alunos que frequentaram o programa e vieram a se envolver com situações de drogas e violência. Trata-se de um trabalho mais complexo necessitando de parcerias como a Policia Militar e seu acervo de dados, implicando em autorizações legais para acesso a dados internos. 


\section{REFERÊNCIAS}

BRASIL. Lei no 11.343/2006, 23 de agosto de 2006. Institui o Sistema Nacional de Políticas Sobre Drogas - SISNAD. Disponível em < www.planalto.gov.br>. Acesso em 12 Nov.18.

. Lei no 9.394/96. De 20 de dezembro de 1996. Estabelece as diretrizes e bases da educação nacional. Disponível em < http://www.planalto.gov.br/ccivil_03/LEIS/L9394.htm>. Acesso em 15 nov.18.

. Núcleo de Estudos da Violência da Universidade de São Paulo. Manual de Policiamento Comunitário: Polícia e Comunidade na Construção da Segurança. Dados eletrônicos. - 2009. Disponível em <https://jundiai.sp.gov.br/administracao-egestao-de-pessoas/wp-content/uploads/sites/16/2016/02/Manual-PoliciamentoComunitario-SENASP-MJ.pdf>. Acesso em 10 jul. 18.

. Secretaria Nacional de Segurança Pública. Curso Nacional de Instrutores Proerd. Brasília: Ministério da Justiça, 2015.

Lei no 11.274/06, de 6 de fevereiro de 2006. Altera a redação dos arts. 29, 30, 32 e 87 da Lei no 9.394, de 20 de dezembro de 1996, que estabelece as diretrizes e bases da educação nacional, dispondo sobre a duração de 9 (nove) anos para o ensino fundamental, com matrícula obrigatória a partir dos 6 (seis) anos de idade. Disponível em < www.planalto.gov.br>. Acesso em 19 Nov.18.

. Lei no 8069/90, 13 de julho de 1990. Dispõe sobre o Estatuto da Criança e do Adolescente e dá outras providências. Disponível em < www.planalto.gov.br>. Acesso em 19 Nov.18.

Nações Unidas no Brasil. Disponível em<https://nacoesunidas.org/direitoshumanos/>. Acesso em 20 dez.18. 
Parâmetros curriculares nacionais: apresentação dos temas transversais: ética/ Ministério da Educação. Secretaria da Educação Fundamental. 3.ed. Brasília: A Secretaria, 1997. 146p.

Constituição do Estado do Paraná. Curitiba: Imprensa Oficial, 1990.

, Ministério da Justiça e segurança Pública. Disponível em <http://www.justica.gov.br/sua-protecao/politicas-sobre-drogas/prevencao-e tratamento/prevencao/prevencao>. Acesso em 13 dez. 18

DALLA VECCHIA, Marcelo. Drogas e direitos humanos : reflexões em tempos de guerra às drogas. [et al.] organizadores. - 1.ed. - Porto Alegre : Rede UNIDA, 2017. 396 p.: il. - (Série Interlocuções práticas, experiências e pesquisas em saúde), acesso 14 fev. 19.

DEMETRIO, Antonio Joel; VIANA, Giomar; HOEFLICH, Vitor Afonso. Um Estudo Sobre o Nível de Eficiência do Programa Educacional de Resistência às DrogasPROERD. Revista Capital Científico - Eletrônica (RCCe) - ISSN 2177-4153 - Volume 11 n.2 - Maio/Agosto 2013. Acesso em 20 fev.19.

Legislação e Políticas Públicas sobre Drogas no Brasil.— Brasília: Ministério da Justiça, Secretaria Nacional de Políticas sobre Drogas, 2011. 106 p.

MELO, Alessandro de. Relações entre escola e comunidade. Curitiba: Ibpex, 2011. MICHALISZYN, Mario Sergio. Educação e diversidade. Curitiba: InterSaberes, 2012.

PARANÁ, Secretaria da Segurança Pública e Administração Penitenciaria. Disponível em $<$ http://www.seguranca.pr.gov.br/modules/conteudo/conteudo.php?conteudo=28>. Acesso em 10 dez.18. 
Prevenção às Drogas e às Violências, 2006. Disponível em $</$ repositorio.ufsc.br/handle/123456789/74645/browse?value=Rateke\%2C+Deise\&ty pe=author $>$. Acesso em 13 de out. 18 .

PMPR, Cap. Perovano -. Apresentação. 2018. Disponível em: <(fonte: http://www.proerdbrasil.com.br/oproerd/oprograma.htm>. Acesso em: 28 nov. 2018.

RATEKE, Deise. A Escola Pública e o PROERD: Tramas do Agir Policial na Prevenção às Drogas e às Violências, 2006. Disponível em https://repositorio.ufsc.br/handle/123456789/74645/browse?value=Rateke\%2C+Deis e\&type=author. Acesso em 12 de setembro de 2018.

SEVERINO, Antônio Joaquim. Metodologia do Trabalho Científico. 23 ed. rev. e atual, - São Paulo: Cortez, 2007.

SOARES, Ticiana Lima; Gomes, Fábio França. Programa Educacional de Resistência às Drogas e à Violência na Paraíba: Desafios e Dificuldades. REBESP, Goiânia, v. 9, n. 2, p. 01-12, 2016. Disponível em <http://revista.ssp.go.gov.br/index.php?journal=rebesp\&page=article\&op=view\&path $\% 5 B \% 5 D=201>$. Acesso em 15 dez.18.

\section{APÊNDICE - REFERÊNCIAS DE NOTA DE RODAPÉ}

2. Com as alterações trazidas pela lei $n^{\circ} 11.274 / 2006$, em seu artigo $3^{\circ}$ "O art. 32 da Lei $\mathrm{n}^{0}$ 9.394, de 20 de dezembro de 1996, passa a vigorar com a seguinte redação: "Art. 32. O ensino fundamental obrigatório, com duração de nove (nove) anos, gratuito na escola pública, iniciando-se aos 6 (seis) anos de idade, terá por objetivo a formação básica do cidadão [...]", passou-se a se aplicar o programa para os alunos da quinta série, em virtude desta alteração algumas passagens do texto constam como quarta série outras como quinta série.

Enviado: Abril, 2019.

Aprovado: Maio, 2020. 